\title{
High-dose ivermectin in malaria and other parasitic diseases: a new step in the development of a neglected drug
}

\author{
Olivier Chosidow ${ }^{1,2,3, a,{ }^{*}}$ Charlotte Bernigaud ${ }^{1,4}$, and Giao Do-Pham ${ }^{5}$ \\ ${ }^{1}$ Department of Dermatology, Hôpital Henri-Mondor, AP-HP, Créteil, France \\ 2 Research group EpiDermE (Epidémiologie en Dermatologie et Evaluation des Thérapeutiques) EA 7379, \\ Université Paris-Est Créteil Val-de-Marne, Créteil, France \\ ${ }^{3}$ French Satellite of the Cochrane Skin Group, Créteil, France \\ ${ }^{4}$ Research Group Dynamyc, EA7380, Ecole nationale vétérinaire d'Alfort, Maisons-Alfort, Université Paris-Est Créteil, \\ Créteil, France \\ ${ }^{5}$ Department of Internal Medicine, Centre Hospitalier Intercommunal de Créteil, Créteil, France
}

Received 3 June 2018, Accepted 25 June 2018, Published online 16 July 2018

\begin{abstract}
We highlight the absence of high-level evidence from dose-ranging studies regarding the use of oral ivermectin in susceptible parasitic diseases. We provide published data supporting the use of a higher dosage regimen of ivermectin in malaria and difficult-to-treat head lice, and announce an ongoing randomized clinical trial in severe scabies.
\end{abstract}

Key words: Oral ivermectin, High doses, Malaria, Head lice, Scabies.

Résumé - Ivermectine à forte dose dans le paludisme et d'autres maladies parasitaires : une nouvelle étape dans le développement d'un médicament négligé. Nous soulignons l'absence de données probantes de haut niveau sur les études de dosage concernant l'utilisation de l'ivermectine par voie orale dans les maladies parasitaires sensibles. Nous fournissons des données publiées soutenant l'utilisation d'un régime plus élevé d'ivermectine dans le paludisme et les poux de tête difficiles à traiter, et nous annonçons un essai clinique randomisé en cours dans la gale sévère.

In a recent issue of the Lancet Infectious Diseases Journal, Smit et al. [12] reported a randomized clinical trial showing the good efficacy/tolerability ratio of a high-dose regimen of ivermectin (i.e., $300 \mu \mathrm{g} / \mathrm{kg}$ per day for 3 days) in uncomplicated malaria. Indeed, oral ivermectin is one of the major weapons against various parasitic diseases such as onchocerciasis and helminthiasis, and in 2015, Omura and Campbell received the Nobel Prize in Medicine for their discovery. However, the clinical development of ivermectin lacks high-level dose-ranging studies, and the dose of $150-200 \mu \mathrm{g} / \mathrm{kg}$ was considered the standard regimen for years for millions of people presenting ivermectin-susceptible parasitic diseases (https://www.accessdata.fda.gov/drugsatfda_docs /label/2008/050742s022lbl.pdf [9]).

In the 1990s, clinical and parasitological resistance [2], followed by genetic resistance [8] of head lice to the neuro-toxic effects of pyrethroid insecticides was found, leading to the dis covery of therapeutic alternatives. Since lice are blood-feeding parasites, oral ivermectin $200 \mu \mathrm{g} / \mathrm{kg}$ was conceptually an interesting option, but the efficacy was disappointing because

\footnotetext{
*Corresponding author: olivier.chosidow@aphp.fr ${ }^{\mathrm{a}}$ Member of the steering committee of IACS (International Alliance for the Control of Scabies) (www.controlscabies.org)
}

a single dose eradicated head lice infestation in only 6 of 26 subjects $(23 \%)$ in a non-controlled study [6].

Unpublished in-house company data from Merck Sharpe \& Dohme-Chibret led to the use of ivermectin $400 \mu \mathrm{g} / \mathrm{kg}, 7$ days apart, which was compared to $0.5 \%$ malathion lotion insecticide in a household-cluster randomized clinical trial [4]. The superiority of the high-dose ivermectin regimen in patients with difficult-to-treat head lice was clearly demonstrated $(95.2 \%$ of patients receiving ivermectin were lice-free on day 15 , as compared with $85.0 \%$ of those receiving malathion: absolute difference, 10.2 percentage points; $95 \%$ confidence interval, 4.6-15.7; $p<0.001)$. The frequency of adverse events did not differ between the two treatment groups.

Cases of scabies reach around 100-130 million yearly, and the condition is distributed worldwide [1]. It represents a significant global burden [3, 7], involving school absenteeism, psycho-social impacts, and impetigo and its complications, in particular in low-resource countries. This explains why scabies has recently been added to the WHO's list of neglected tropical diseases (http://www.who.int/neglected_diseases/diseases/en). Oral ivermectin and topical 5\% permethrin are considered the drugs of choice in many countries (topical benzyl benzoate may be used too) [5]. In classical scabies (with a limited number of mites on the skin), although ivermectin at $200 \mu \mathrm{g} / \mathrm{kg}$ seems the 
drug of choice for mass administration [10], a recently published Cochrane systematic review did not detect a large difference with $5 \%$ topical permethrin at week 2 (with low-certainty evidence) [11]. From our previous findings in head lice, we hypothesize that a higher dosage of ivermectin could be more appropriate, especially in patients with highly parasitized severe scabies. Therefore, we are conducting a French Ministry of Health-approved randomized clinical trial (Programme Hospitalier de Recherche Clinique 2014 AOM14612) in severe scabies (i.e., profuse and crusted scabies, with dozens to millions of mites on the skin), comparing ivermectin $400 \mu \mathrm{g} / \mathrm{kg}-200 \mu \mathrm{g} / \mathrm{kg}, 3$ doses, 7 days apart (in combination with 5\% topical permethrin and emollients in both groups) (https://clinicaltrials.gov; NCT02841215).

We believe that a high-dose ivermectin regimen should be better investigated in parasitic diseases, as has been done in malaria and ectoparasitosis.

\section{Conflicts of interest}

Olivier Chosidow: Research grant from Codexial, Speaker fees from Zambon and Codexial; Charlotte Bernigaud: Research grant from Codexial; Giao Do-Pham: none.

\section{References}

1. Chosidow O. 2006. Clinical practices. Scabies. New England Journal of Medicine, 354, 1718-1727.

2. Chosidow O, Brue C, Chastang C, Bouvet E, Izri M, Rousset J, Monteny N, Bastuji-Garin S, Revuz J. 1994. Controlled study of malathion and d-phenothrin lotions for Pediculus humanus var capitis-infested schoolchildren. Lancet, 344(8939-890), 1724-1727.

3. Chosidow O, Fuller LC. 2017. Scratching the itch: Is scabies a truly neglected disease? Lancet Infectious Diseases, 17, 1220-1221.

4. Chosidow O, Giraudeau B, Cottrell J, Izri A, Hofmann R, Mann SG, Burgess I. 2010. Oral ivermectin versus malathion lotion for difficult-to-treat head lice. New England Journal of Medicine, 362(10), 896-905.

5. Currie BJ, McCarthy JS. 2010. Permethrin and ivermectin for scabies. New England Journal of Medicine, 362, 717-725.

6. Glaziou P, Nyguyen L, Moulia-Pelat J, Cartel J, Martin P. 1994. Efficacy of ivermectin for the treatment of head lice (Pediculosis capitis). Tropical Medicine and Parasitology, 45(3), 253-254.

7. Karimkhani C, Colombara DV, Drucker AM, Norton SA, Hay R, Engelman D, Steer A, Whitfeld M, Naghavi M, Dellavalle RP. 2017. The global burden of scabies: a cross-sectional analysis from the Global Burden of Disease Study 2015. Lancet Infectious Diseases, 17(12), 1247-1254.

8. Lee SH, Yoon K-S, Williamson MS, Goodson SJ, Takano-Lee M, Edman JD, Devonshire AL, Clark JM. 2000. Molecular analysis of kdr-like resistance in permethrin-resistant strains of head lice, Pediculus capitis. Pesticide Biochemistry and Physiology, 66(2), 130-143.

9. Muñoz J, Ballester MR, Antonijoan RM, Gich I, Rodríguez M, Colli E, Gold S, Krolewiecki AJ. 2018. Safety and pharmacokinetic profile of fixed-dose ivermectin with an innovative $18 \mathrm{mg}$ tablet in healthy adult volunteers. PLoS Neglected Tropical Diseases, 12(1), e0006020.

10. Romani L, Whitfeld MJ, Koroivueta J, Kama M, Wand H, Tikoduadua L, Tuicakau M, Koroi A, Andrews R, Kaldor JM. 2015. Mass drug administration for scabies control in a population with endemic disease. New England Journal of Medicine, 373(24), 2305-2313.

11. Rosumeck S, Nast A, Dressler C. 2018. Ivermectin and permethrin for treating scabies. Cochrane Database of Systematic Reviews, 4, CD012994-CD012994.

12. Smit MR, Ochomo EO, Aljayyoussi G, Kwambai TK, Abong'o BO, Chen T, Bousema T, Slater HC, Waterhouse D, Bayoh NM, Gimnig JE, Samuels AM, Desai MR, Phillips-Howard PA, Kariuki SK, Wang D, Ward SA, ter Kuile FO. 2018. Safety and mosquitocidal efficacy of high-dose ivermectin when coadministered with dihydroartemisinin-piperaquine in Kenyan adults with uncomplicated malaria (IVERMAL): a randomised, double-blind, placebo-controlled trial. Lancet Infectious Diseases, 18(6), 615-626.

Cite this article as: Chosidow O, Bernigaud C \& Do-Pham G. 2018. High-dose ivermectin in malaria and other parasitic diseases: a new step in the development of a neglected drug. Parasite 25, 33.

\section{PARASTE}

An international open-access, peer-reviewed, online journal publishing high quality papers on all aspects of human and animal parasitology

Reviews, articles and short notes may be submitted. Fields include, but are not limited to: general, medical and veterinary parasitology; morphology, including ultrastructure; parasite systematics, including entomology, acarology, helminthology and protistology, and molecular analyses; molecular biology and biochemistry; immunology of parasitic diseases; host-parasite relationships; ecology and life history of parasites; epidemiology; therapeutics; new diagnostic tools.

All papers in Parasite are published in English. Manuscripts should have a broad interest and must not have been published or submitted elsewhere. No limit is imposed on the length of manuscripts.

Parasite (open-access) continues Parasite (print and online editions, 1994-2012) and Annales de Parasitologie Humaine et Comparée (1923-1993) and is the official journal of the Société Française de Parasitologie. 